\title{
Biclonal splenic marginal zone lymphoma with T cell-rich background and aggressive transformation to large cell lymphoma
}

\author{
Alia Gupta ${ }^{1} \cdot$ Amy Gabbard $^{1} \cdot$ Marc D. Smith ${ }^{1,2} \cdot$ Mark Micale $^{1,2} \cdot$ Bobby L. Boyanton Jr ${ }^{1,2} \cdot$ James Huang ${ }^{1,2}$
}

Received: 7 December 2018 / Accepted: 26 March 2019 /Published online: 5 April 2019

(C) Springer-Verlag GmbH Germany, part of Springer Nature 2019

\begin{abstract}
Marginal zone B cell lymphomas (MZL) are biologically heterogeneous, rarely demonstrating biclonality, complex cytogenetic abnormalities, or T cell predominance. We report a case of biclonal splenic MZL, T cell-rich variant with an abnormal karyotype that progressed to large B cell lymphoma. A 74-year-old female presented with pancytopenia, weight loss, fever, and splenomegaly. Microscopically, the spleen revealed an extensive, vaguely nodular lymphoid proliferation, composed of small lymphocytes, majority of which were reactive T cells. B cells were mostly small and $<5 \%$ of total lymphocytes. Focal follicular dendritic cell networks were present, but germinal centers were absent. Flow cytometric analysis revealed two distinct CD5 and CD10 negative B cell clones, one kappa positive and one lambda positive. Conventional cytogenetic analysis revealed the following abnormal karyotype: 47,XX, add(7)(q36),del(7)(q22), add(21)(p11.2), $+\operatorname{mar}[10] / 46, X X[10]$. Immunoglobulin heavy chain gene rearrangement showed two monoclonal peaks of different magnitude, consistent with biclonality. Overall, these features favored a low-grade splenic MZL. The staging bone marrow biopsy was normocellular with few interstitial lymphoid aggregates, composed of small lymphocytes, consistent with minimal involvement by low-grade B cell lymphoma. The patient improved without adjuvant chemotherapy; however, 12 months later, she developed anemia and lymphocytosis. Subsequent bone marrow biopsy showed extensive involvement by a large B cell lymphoma and complex karyotype with the previously identified abnormalities, as well as additional numerical and structural aberrations, consistent with cytogenetic evolution and biclonal gene rearrangement. These findings were consistent with transformation. This case demonstrates a unique pathological presentation of splenic MZL with disease progression, highlighting the importance of an integrated approach for lymphoma classification and the difficulties in diagnosing such cases.
\end{abstract}

Keywords Marginal zone lymphoma $\cdot$ T cell-rich variant

\section{Introduction}

Splenic marginal zone lymphoma (SMZL) is a rare, indolent B cell non-Hodgkin lymphoma (NHL), accounting for $0.9 \%$ of all NHLs. Categorized as a discrete entity in 1991, it is the second most common subtype of MZL [1, 2]. It originates from memory B cells of the marginal zone of secondary lymphoid follicles and is characterized by the presence of small B lymphocytes which distort the normal follicular architecture of the spleen [1].

James Huang

James.Huang@beaumont.edu

1 Department of Pathology and Laboratory Medicine, Beaumont Health, 3601 West 13 Mile Road, Royal Oak, MI 48073, USA

2 Department of Pathology and Laboratory Medicine, Oakland University William Beaumont School of Medicine, Rochester, MI, USA
No distinctive recurrent chromosomal anomalies have been documented in SMZL. Only a few genetic aberrations have been reported so far, contrasting with other B cell NHLs with well-established cytogenetic changes. Association with $\operatorname{IgV}_{\mathrm{H}}$ mutations is consistent with their post follicular marginal zone B cell origin [3]. Hereby, we report the first case of SMZL with a $\mathrm{T}$ cell and histiocytic-predominant background with only a small population of interspersed neoplastic B cells. Our patient also showed biclonality, with the presence of two different monotypic B cell clones.

\section{Materials and methods}

Peripheral blood, bone marrow, and solid tissue (splenectomy and liver biopsy) were submitted and processed in the Department of Pathology and Laboratory Medicine, Beaumont Health, according to established protocols. 
For the bone marrow specimen, an aspirate, clot section, and biopsy were prepared. The aspirates were distributed into the appropriate anticoagulant (EDTA or sodium heparin-containing tubes) for additional required special testing (flow cytometry, cytogenetics, molecular, etc.), and the bone marrow core biopsy and aspirate clot were submitted in B-Plus Fix containers. The tissue biopsies were submitted in formalin, processed, and stained with hematoxylin and eosin or other special and immunohistochemical stains, as required.

\section{Immunophenotyping}

The specimens for flow cytometry were collected in EDTA or sodium heparin tubes (for blood and bone marrow) or in tissue culture medium (RPMI) when tissue biopsies were submitted. They were analyzed using a multiparameter 10 color flow cytometer. Blood and bone marrow specimens were maintained at room temperature $\left(20-26^{\circ} \mathrm{C}\right.$ or $\left.68-78.8^{\circ} \mathrm{F}\right)$, whereas body fluids and solid tissue were refrigerated $\left(2-8{ }^{\circ} \mathrm{C}\right.$ or $36-$ $\left.46^{\circ} \mathrm{F}\right)$. The antibody panel was determined by the clinical history and/or review of stained slides.

\section{Molecular and cytogenetic analyses}

$\mathrm{B}$ and $\mathrm{T}$ cell gene rearrangements were performed on EDTA bone marrow and formalin-fixed paraffin-embedded tissue. Prior to testing, DNA quality and quality was assessed for minimal acceptance $\left(260_{\mathrm{nm}} / 280_{\mathrm{nm}}\right.$ ratio $>1.8$ and $50 \mathrm{ng} / \mu \mathrm{l}$ ) by UV spectrophotometry (NanoDrop-1000; ThermoFisher). DNA was extracted and PCR-amplified using specific primer sets targeting the framework (forward primers) and joining (reverse primers) regions of the $I G H$ and TCR-gamma genes. Analysis was performed via automated capillary electrophoresis (ABI 310; ThermoFisher), followed by Pathologist's interpretation.

Preparation of metaphase chromosomes for conventional cytogenetic analysis was performed according to established methods and analyzed using the Leica Cytovision $®$ platform for digital karyotype analysis.

\section{Clinical history and results}

A 74-year-old female presented with a complaint of unintentional $50 \mathrm{lbs}$. weight loss, as well as, back pain, and failure to thrive for the past 2 years. She also complained of fever with chills, palpitations, and abdominal pain. A complete blood count (CBC) showed pancytopenia, and imaging revealed splenomegaly and hepatomegaly (likely attributed to fatty liver). Overall, these findings were concerning for a hematologic neoplasm, possibly lymphoma. The initial diagnostic workup included a bone marrow biopsy (bone marrow-1), which was normocellular with a few small nodular lymphoid aggregates (Fig. 1). The aggregates were mainly composed of small $\mathrm{T}$ cells with a normal CD4:CD8 ratio. A minor population of small, scattered B cells (CD20 positive) was also present. Concurrent flow cytometry showed similar findings with increased $\mathrm{T}$ cells with a normal $\mathrm{CD} 4: \mathrm{CD} 8$ ratio and no aberrant antigenic expression. B cells accounted for $<1 \%$ of the total lymphocytic population and demonstrated polyclonality. Cytogenetic studies revealed a normal female karyotype. The initial interpretation favored reactive lymphoid aggregates. PCR for immunoglobulin heavy chain gene rearrangement was retrospectively performed after splenic B cell lymphoma was made. Monoclonal gene rearrangements identical to that seen in the spleen and hilar lymph node were identified in the bone marrow. The interpretation was then revised as consistent with early bone marrow involvement by B cell lymphoma.

Serologic and molecular tests for hepatitis B were negative. A liver core biopsy was performed, which showed a few lymphoid aggregates, mainly confined to the portal tracts with a few scattered within the hepatic lobules. The hepatic parenchyma showed minimal steatosis with no fibrosis, necrosis, or ballooning of hepatocytes. The lymphoid aggregates were composed of mostly $\mathrm{T}$ cells with admixture of CD4 and CD8 subsets. T cells showed normal expression of CD5 and they primarily expressed the TCR beta subunit. Rare scattered small B cells were present. EBV EBER in situ hybridization (ISH) was negative. The overall findings were again noncontributory to the clinical findings.

Subsequently, the patient underwent a splenectomy. Grossly, the spleen weighed $2330 \mathrm{~g}$ and measured $29.5 \times$ $20.2 \times 9.5 \mathrm{~cm}$ (Fig. 2a). The cut surface showed multiple, 0.1 to $0.5 \mathrm{~cm}$ white, pale nodules distributed throughout the splenic parenchyma. On microscopic examination, the normal splenic architecture was distorted by micronodular and macronodular lymphocytic infiltrates which were mainly composed of small to medium lymphocytes (Fig. 2b-d). No germinal centers were identified. On immunohistochemical staining, lymphocytes were composed of mostly $\mathrm{T}$ cells with scattered B cells which were mostly small. Occasional larger or large cells were seen (Fig. 2e-h). The CD20 positive B cells showed similar intensity and staining pattern with PAX5 and CD79a. The number of CD20 positive cells and CD79a positive B cells were very similar. There was no overt evidence of plasmacytoid or plasmacytic differentiation. The size of the B and T cells was similar. Rare residual follicular dendritic cell networks were identified using CD23 and CD21. CD15 mostly stained the granulocytes. CD30 showed scattered positivity but with no definite co-expression of CD15. The Ki67 index was $20-30 \%$. EBER ISH was negative. Fresh tissue from the spleen and splenic hilar lymph nodes was submitted for flow cytometric evaluation. Both the spleen and hilar lymph node 
Fig. 1 The pathological features of the first bone marrow biopsy. There are scattered small lymphoid aggregates $(\mathbf{a} \times 400$; $\mathbf{b}$ $\times 1000)$. Small lymphocytes are predominantly $\mathrm{T}$ cells $(\mathbf{c} \mathrm{CD} 3, \times$ $1000 ; \mathbf{d}$ CD20, $\times 1000)$. No significant large atypical lymphoid cells are seen

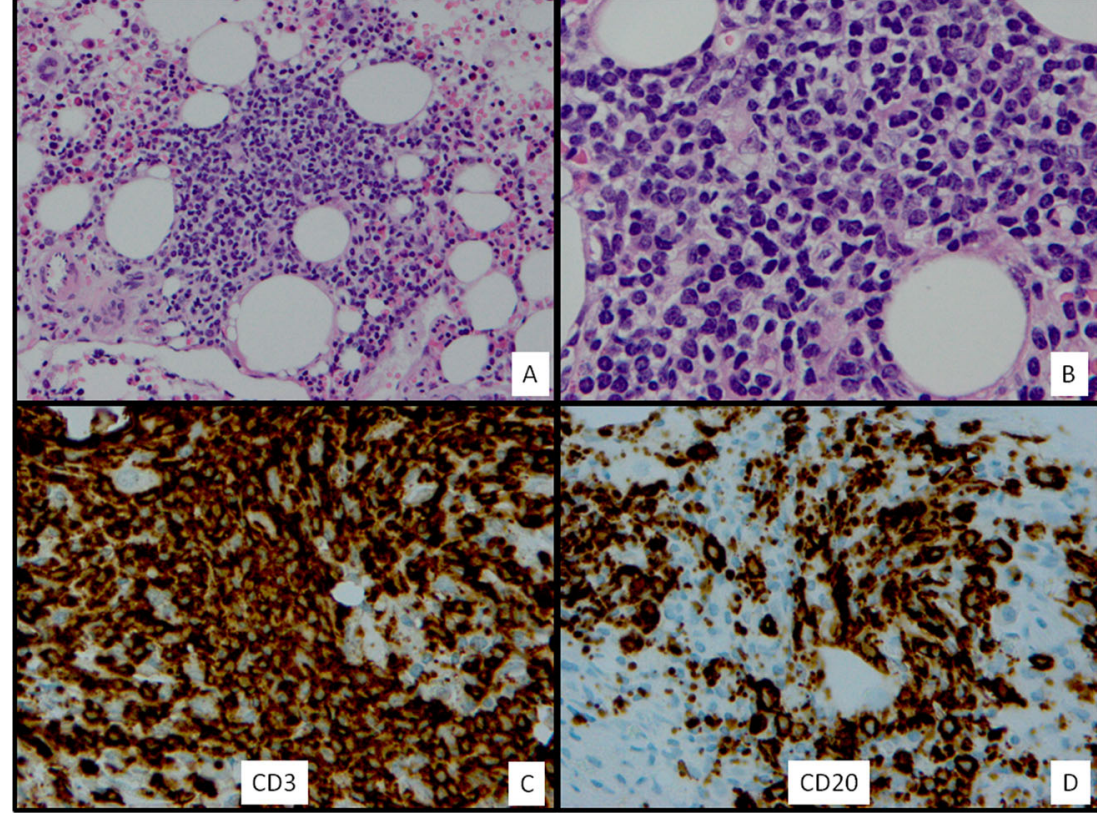

showed similar flow cytometric findings. As shown in Fig. 3, approximately $98.5 \%$ of the lymphocytes in the spleen were composed of an admixture of CD4 and CD8 positive T cells with no aberrant antigenic expression. B cells accounted for the remaining $1.5 \%$. The overall kappa:lambda ratio of $\mathrm{B}$ cells suggested no light chain restriction. However, kappa positive and lambda positive B cells showed different intensity of expression for $\mathrm{CD} 22$ and bcl-2, consistent with two separate monotypic B cell populations: one kappa restricted, the other lambda restricted. Both of the neoplastic B cell populations were positive for $\mathrm{CD} 19$ and CD79a but negative for $\mathrm{CD} 5$ and $\mathrm{CD} 10 . \mathrm{B}$ and $\mathrm{T}$ cell gene rearrangement testing was performed on the spleen and splenic hilar lymph node. T cell receptor-gamma (TCR-gamma) gene rearrangement was negative (polyclonal). IGH heavy chain gene rearrangement was positive, exhibiting two monoclonal peaks (121-122 bp and 129-130 bp) with the framework 3 primer set. Due to DNA degradation, the framework 1 and 2 primer sets could not be analyzed. The magnitude of the peaks in the framework 3 primer set was approximately equal in height, supportive of (a) a biclonal process or (b) a bi-allelic monoclonal gene rearrangement (Fig. 5). Cytogenetic studies of the spleen and splenic hilar lymph nodes showed an abnormal karyotype: 47,XX, add(7)(q36), del(7)(q22), add(21)(p11.2),+mar[10]/ 46,XX[10]. A diagnosis of low-grade B cell lymphoma was made in the spleen and splenic hilar lymph nodes. Overall, features favored an unusual splenic marginal zone lymphoma.

Since the spleen and splenic hilar lymph nodes were positive for involvement by lymphoma, bone marrow-1 and the liver biopsies were re-evaluated, and $I G H$ gene rearrangement studies were performed. Bone marrow-1 showed two monoclonal peaks (larger magnitude was 121-122 bp, smaller magnitude was 129-130 bp) with the framework 3 primer set consistent with involvement by B cell NHL (Fig. 4). Considered in isolation, the two peaks of similar size identified in the spleen could represent a biclonal or bi-allelic process; however, the change in magnitude of the two peaks in the bone marrow strongly favors a biclonal process, as this discordance is much more likely to be the result of two different cell populations. The quality and quantity of DNA isolated from the liver biopsy were insufficient for $I G H$ gene rearrangement evaluation.

Given the indolent nature of the disease, the patient did not undergo adjuvant chemotherapy. She responded well to splenectomy and her $\mathrm{CBC}$ showed improving counts. She was followed-up regularly as an outpatient in the oncology clinic. One year after her splenectomy, she complained of increasing fatigue, weakness, decreased appetite, and weight loss. A CBC showed leukocytosis, with lymphocytosis, eosinophilia, basophilia, and mild anemia. She also had markedly elevated serum calcium and ionized calcium levels, which were attributed to hypercalcemia of malignancy, given her normal parathyroid hormone and phosphorous levels. A PET scan showed moderate, increased diffuse FDG-avid activity in the bone marrow. A second bone marrow biopsy (bone marrow-2) was performed, which showed a hypercellular marrow (90\%) with infiltration by predominantly small lymphocytes and histiocytes. Scattered among the smaller cells were a few large atypical cells (Fig. 5). On immunohistochemical staining, the large cells were B cells, positive for CD20, CD79a, and PAX5. The small lymphocytes in the background were positive for CD3 and CD5. 
Fig. 2 The pathological features of the spleen. Gross section from the formalin-fixed spleen showing multiple very small whitish nodules scattered throughout the splenic parenchyma (a). The HE section showing the presence of nodular lymphoid proliferation $(\mathbf{b} \times 40$; $\mathbf{c}$ $\times 200 ; \mathbf{d} \times 500$ ). Lymphocytes are small to medium in size. No significant large atypical cells are seen. The lymphoid nodules showing $\mathrm{T}$ cell predominance with scattered small B cells $(\mathbf{e}, \mathbf{f} \times$ $200 ; \mathbf{g}, \mathbf{h} \times 400$ )
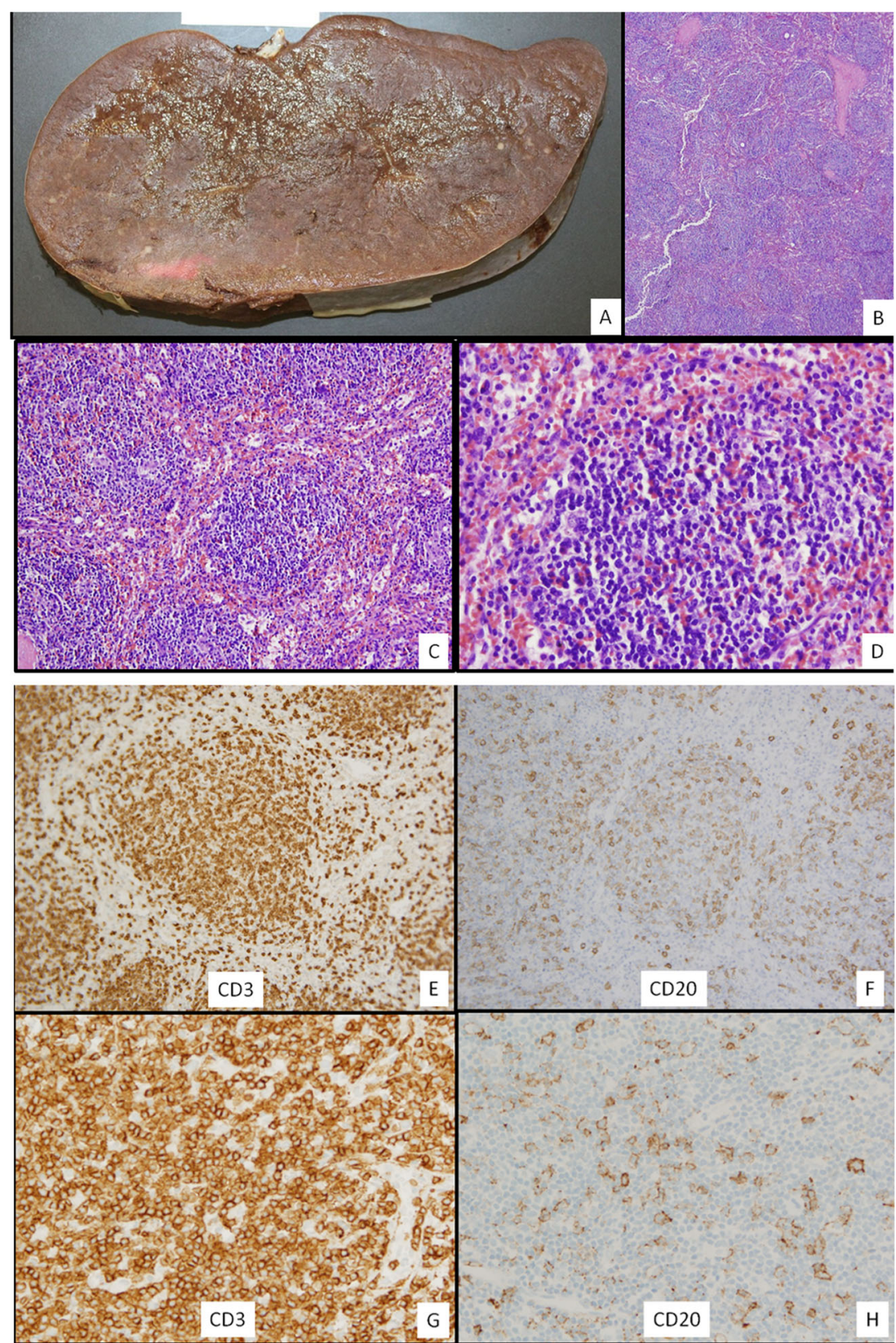

Flow cytometry did not show any immunophenotypic evidence of light chain restriction, $\mathrm{T}$ cell antigenic aberrancy or increased blasts. Bone marrow cytogenetic evaluation revealed a more complex karyotype compared with that observed previously: 45,X,-X[3]/47,XX,+3, der(3;21)(q10;q10),add(5)(q35),+ $\mathrm{i}(5)(\mathrm{p} 10), \operatorname{add}(7)(\mathrm{q} 36), \operatorname{del}(\mathrm{7})(\mathrm{q} 22)$. The abnormal cell line with loss of an X chromosome was a new finding, not observed in the spleen. Taken together, these findings were interpreted to represent aggressive transformation/progression of lowgrade B cell lymphoma to large B cell lymphoma with a $\mathrm{T}$ cell-/histiocyte-rich background and cytogenetic evolution. Concomitantly, an $I G H$ gene rearrangement study was performed on bone marrow- 2 and showed two monoclonal peaks (larger magnitude was 129-130 bp, smaller magnitude was $121-122 \mathrm{bp}$ ) with the framework 3 primer set (not shown), indicative of the biclonal process.

\section{Discussion}

SMZL is a rare type of NHL which usually affects patients in the age group of 22-79 years with a mean age of 68 years [4]. In 1992, Schmid et al. described the term splenic marginal zone lymphoma as a small B cell lymphoma involving the spleen and bone marrow, characterized by a micronodular tumor infiltrate distorting the preexisting lymphoid follicles with a distinct marginal zone differentiation [5]. The WHO classification describes 
Fig. 3 The flow cytometric features of the spleen. The majority of the lymphocytes are $\mathrm{T}$ cells, with two B cell populations with varying expression of bcl-2 (a). The majority of the lymphocytes are small with low forward scatter (b). The population with less bcl-2 expression is kappa-monotypic and the population with bcl-2 overexpression is lambdamonotypic based on surface (c) and cytoplasmic (d) light chain stain patterns
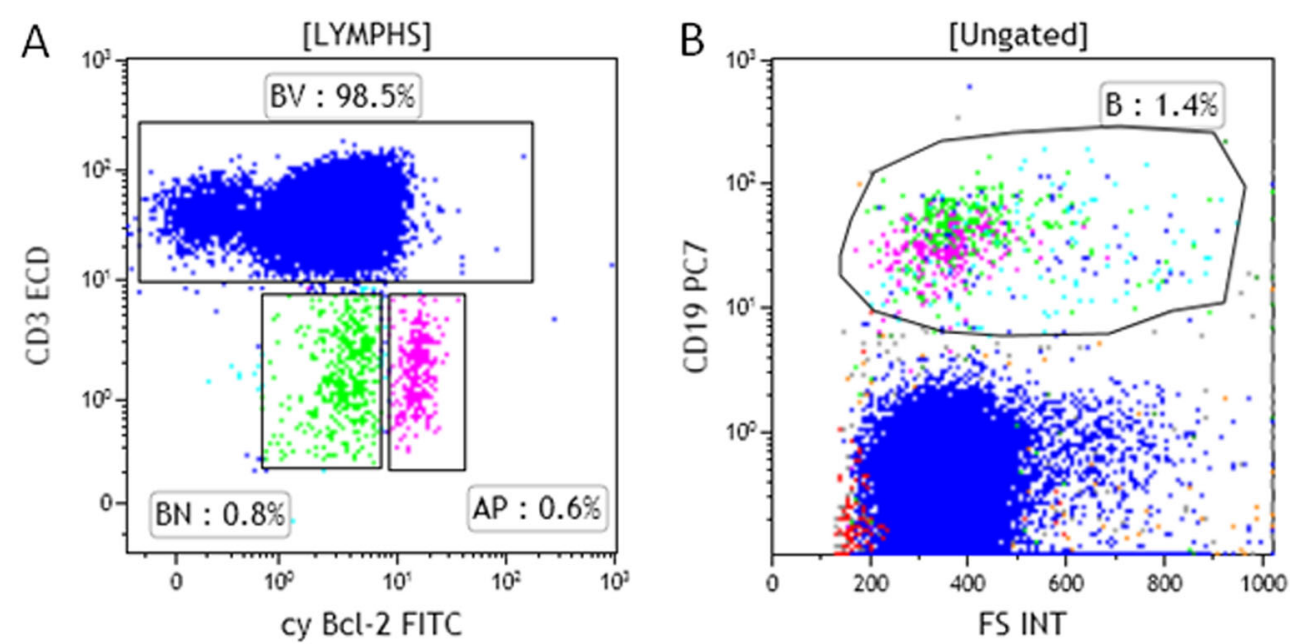

C

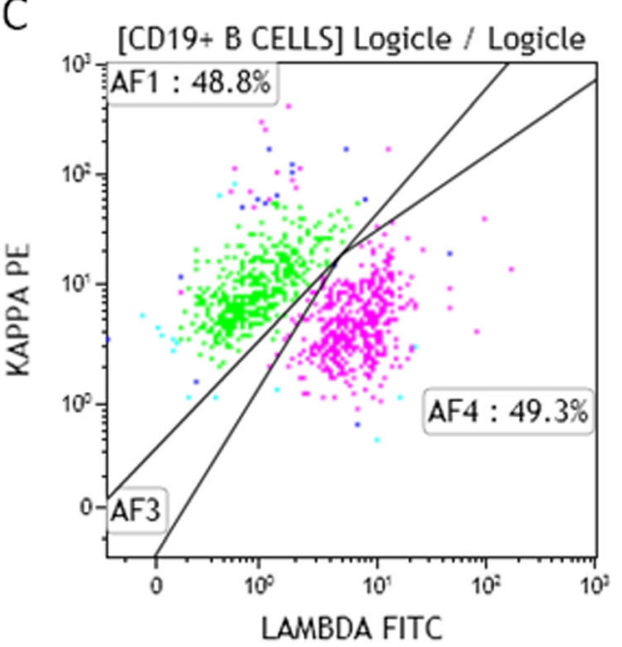

D

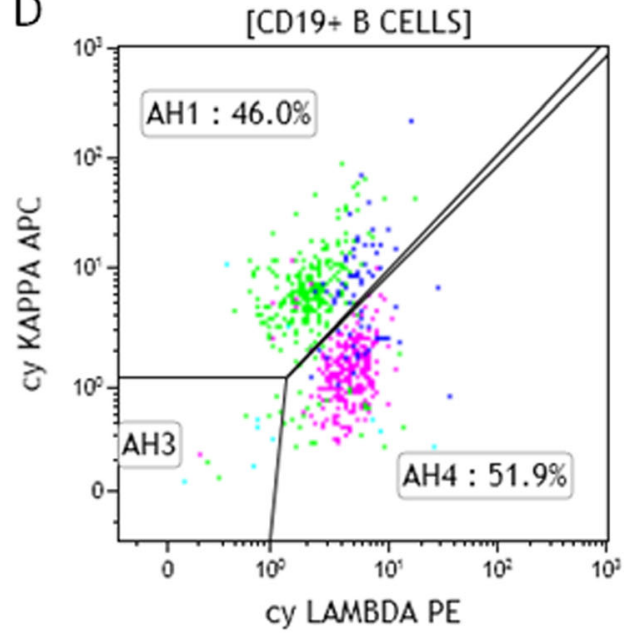

SMZL as a B cell neoplasm composed of small lymphocytes that surround and replace splenic white pulp and efface the follicle mantle. The peripheral zone is comprised of marginal zone cells which are small to medium-sized cells with abundant pale cytoplasm and dispersed chromatinalong with scattered transformed blasts. Sinusoidal invasion is often seen and is better visualized by CD20 staining [6]. Our patient's specimens had similar architectural distortion; however, the majority of the lymphocytic population was comprised of reactive $T$ cells. The neoplastic small B cells were far fewer in number compared with typical splenic marginal zone B cell lymphoma. Micronodular T cell-/histiocyte-rich large B cell lymphoma was in the differential diagnosis, but was unlikely given the relatively indolent clinical presentation that is characteristic of low-grade lymphomas. Histologically, most B cells were small with occasional larger or large B cell seen. The size variation of neoplastic B cells appeared within the spectrum of marginal zone B cell lymphoma. We could not identify significant large B cells as described in the literature to support the diagnosis [7]. Initially, we considered a diagnosis of splenic B cell lymphoma/ leukemia unclassifiable. However, after we received the cytogenetic karyotyping results, splenic marginal zone lymphoma was favored. Based on the literature, about $30 \%$ of splenic marginal zone lymphomas show a heterozygous deletion of $7 \mathrm{q}$, which is rarely found other subtypes of lymphomas [6].

Reactive $\mathrm{T}$ cells are typically more abundant in marginal lymphoma than other low-grade B cell lymphomas. Magro and Geyer et al. described a few cases of cutaneous T cell-rich MZL with plasmacytic differentiation, which showed an abundance of reactive $\mathrm{T}$ cells $[8,9]$. Other B cell lymphomas of the skin can also show abundant reactive $T$ cells [10]. Our case showed reactive $T$ cells greater than $98 \%$ of lymphocytes and neoplastic B cells less than $2 \%$ based on flow cytometric data and confirmed by immunohistochemistry with CD20, CD79a, and PAX5. The paucity of neoplastic B cells, to this degree, has not been reported in splenic marginal zone lymphomas. This case also illuminates the difficulty in making this diagnosis with limited tissue such as a fine needle aspiration or core biopsy, as the diagnosis was initially missed in the liver and bone marrow. 

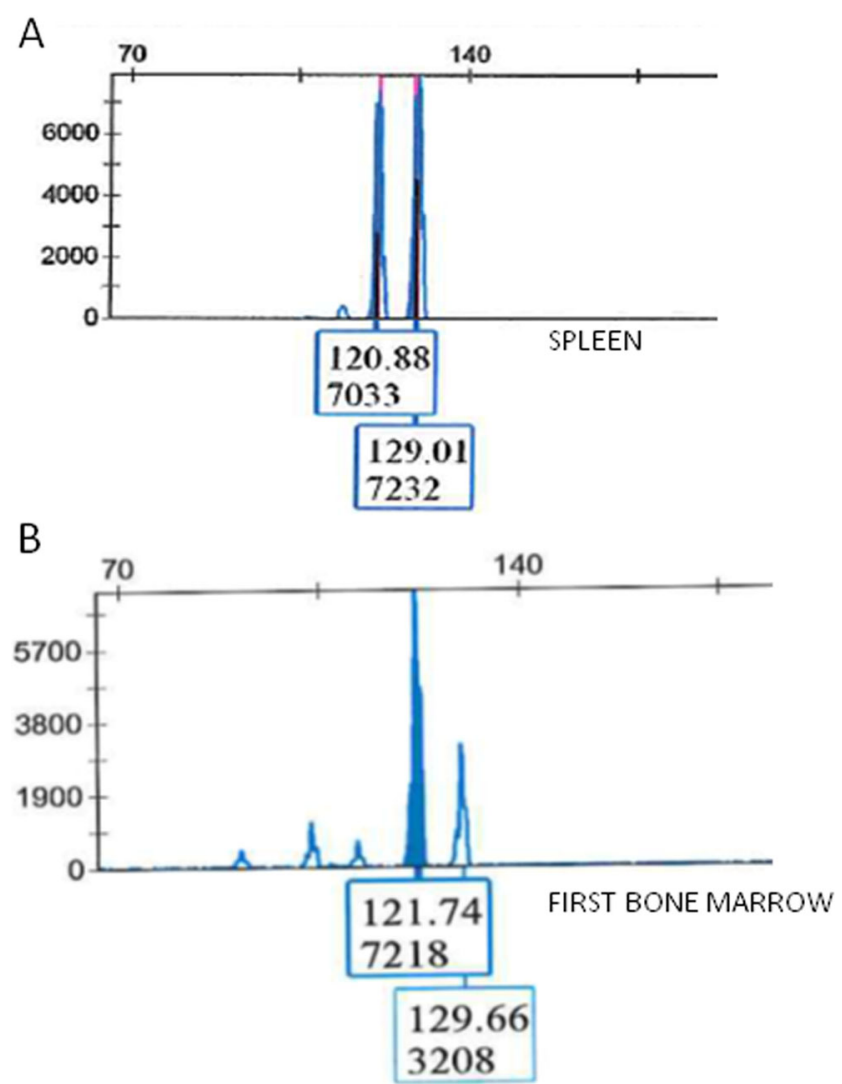

Fig. 4 IgH PCR assay showing IgH gene rearrangement. Both spleen (a) and bone marrow-1 (b) show two identical monoclonal peaks - PCR amplicon sizes generated with framework 3 primer set

What makes this case more interesting is the presence of biclonality in the small B cells, showing one kappa restricted and one lambda restricted population. This finding was consistent with molecular analysis, which showed separate monoclonal peaks by PCR. Delville et al. reported similar findings in a biclonal low-grade B cell lymphoma, which had a normal kappa/lambda Ig light chain ratio in the blood. The biclonality was confirmed after analyzing different tissues with the help of various ancillary testing methods, including flow cytometry both analytical and cell sorting, molecular biology, and cytogenetics [11]. Another study by Sanchez et al. also studied the incidence and clinico-biologic characteristics of leukemic B cell chronic lymphoproliferative disorders with more than one B cell clone. They found that $25 \%$ of their study population demonstrated different surface immunoglobulin light chain isotypes with identical antigenic expression in the two B cell populations. They stressed the fact that a normal $\mathrm{sIg} / \mathrm{sIg}$ ratio may not be a useful marker of clonality, and the combination of light chain analysis with aberrant antigenic expression would be more sensitive and specific for detecting two or more B cell clones in a Blymphoproliferative disorder. Molecular analysis was necessary in the confirmation of clonality [12].
In 1998, O'Reilly et al. showed that a bone marrow biopsy could be considered the invasive procedure of choice in patients with splenomegaly of unknown origin [13]. This can be helpful, since a splenectomy it is a riskier procedure. This was the approach taken with our patient; however, bone marrow studies were not diagnostic, and a splenectomy was required. Our case suggests that a bone marrow with scarce small lymphoid aggregates, and a predominance of normal T cells admixed with a few small B cells immunophenotypically may not necessarily be reactive. In such cases, evaluation of the clinical history is the key in determining whether bone marrow involvement by $\mathrm{T}$ cell-rich small $\mathrm{B}$ cell lymphoma is a possibility. If the patient has organomegaly or other reasons to suspect lymphoma, molecular studies should be considered to rule out a clonal lymphoid proliferation (even though flow cytometry may be negative). If molecular studies are positive, recommendation for splenectomy or biopsy of enlarged lymph nodes should be made for definitive diagnosis.

SMZL is a low-grade indolent B cell neoplasm with an overall 10-year survival probability of $67-95 \%$. These lymphomas respond poorly to chemotherapy; however, splenectomy, with or without rituximab, helps improve hematological response and overall survival. Our patient did not undergo any chemotherapy and showed significant improvement in CBC counts and clinical symptoms post-splenectomy. However, a year later, she developed large B cell lymphoma with T cell-/histiocyte-rich background, just like the prior low-grade lymphoma. Although the histological features were different in the spleen and subsequent bone marrow (bone marrow-2), similar cytogenetic abnormalities were identified in both, with additional complex karyotypic abnormalities in bone marrow-2, indicating cytogenetic evolution. An aggressive clinical course has been documented in only 5 to $19 \%$ of SMZL cases, some of which may present with transformation into a higher-grade lymphoma [14-16]. Histologically, transformation is characterized by an increased number of larger lymphocytes in the peripheral blood, spleen and/or bone marrow. These cases more frequently show loss of chromosome 7q, NOTCH2 mutation, or p53 inactivation [17]. It is evident by comparison between bone marrow-1, the spleen, and bone marrow2 that the disease transformed from a T cell-/histiocyte-rich small marginal zone B cell lymphoma to a large B cell lymphoma, which was associated with significant cytogenetic evolution. The prognostic significance of T cell-/histiocyterich background in SMZL needs to be investigated further. It is interesting to speculate whether our case may represent a splenic marginal B cell lymphoma at the early stage of transformation into micronodular $\mathrm{T}$ cell-/histiocyte-rich large B cell lymphoma, which eventually transformed into a full-blown T cell-/histiocyte-rich large B cell lymphoma in the bone marrow. Of diagnostic importance, this case 
Fig. 5 The pathological features of second bone marrow biopsy showing $\mathrm{T}$ cell-/histiocyte-rich large B cell lymphoma. Diffuse lymphohistiocytic infiltrate is seen $(\mathbf{a} \times 100 ; \mathbf{b} \times 400 ; \mathbf{c} \times 1000)$ with mostly small lymphocytes and histiocytes. Small lymphocytes are predominantly $\mathrm{T}$ cells and scattered large cells are B cells $(\mathbf{d}$ PAX $5 ; \times 1000 ;$ e CD20, $\times 1000 ; \mathbf{f C D} 3, \times 1000)$

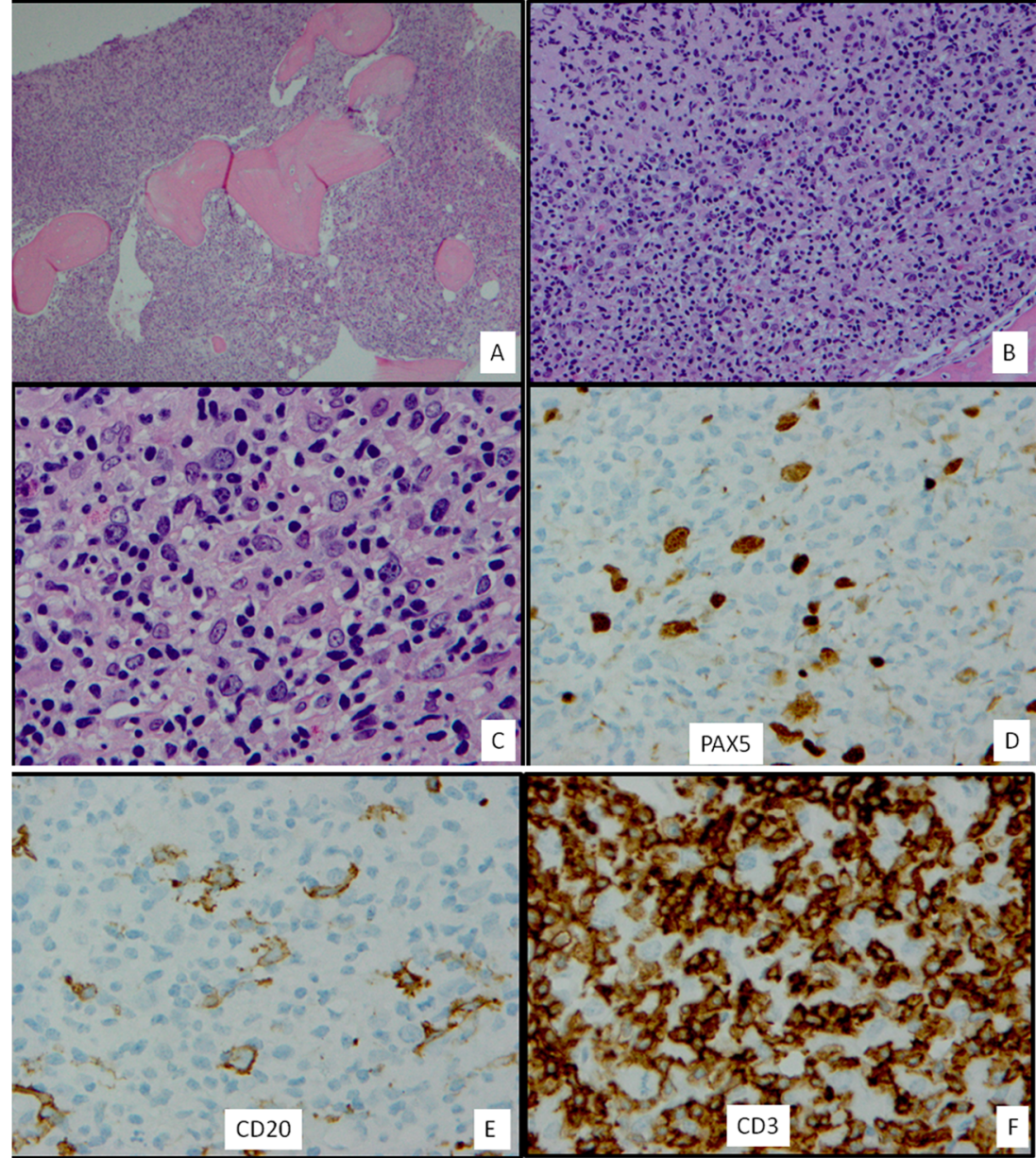

demonstrates that a low-grade B cell lymphoma can demonstrate a T cell-/histiocyte-rich background with a paucity of small B cells. Recognition of these cases can be difficult. Careful assessment of clinical findings and ancillary studies can help avoid misdiagnosis.

Acknowledgments We would like to acknowledge Dr. Mazen Toushan for his help with taking the gross pictures.

\section{Compliance with ethical standards}

Conflict of interest The authors declare that they have no conflict of interest.

\section{References}

1. Zinzani PL (2012) The many faces of marginal zone lymphoma. ASH Educ Progr B 1:426-432

2. Campo E, Swerdlow SH, Harris NL, Pileri S, Stein H, Jaffe ES (2011) The 2008 WHO classification of lymphoid neoplasms and beyond: evolving concepts and practical applications. Blood 117(19):5019-5032

3. Miranda RN, Cousar JB, Hammer RD, Collins RD, Vnencak-Jones CL (1999) Somatic mutation analysis of IgH variable regions reveals that tumor cells of most parafollicular (monocytoid) B-cell lymphoma, splenic marginal zone B-cell lymphoma, and some hairy cell leukemia are composed of memory B lymphocytes. Hum Pathol 30:306-312

4. Franco V, Florena AM, Iannitto E (2003) Splenic marginal zone lymphoma. Blood 101(7):2464-2472

5. Schmid C, Kirkham N, Diss T, Isaacson PG (1992) Splenic marginal zone cell lymphoma. Am J Surg Pathol 16:455-466

6. Swerdlow SH, Campo E, Harris NL et al (2017) Splenic marginal zone lymphoma. In: Swerdlow SH, Campo E, Harris NL et al (eds) WHO classification of tumours of haematopoietic and lymphoid tissues, revised 4th edn. International Agency for Research on Cancer, Lyon, pp 223-225

7. Dogan A, Burke JS, Goteri G, Stitson RNM, Wotherspoon AC, Isaacson PG (2003) Micronodular T-cell/histiocyte-rich large B-cell lymphoma of the spleen: histology, immunophenotype, and differential diagnosis. Am J Surg Pathol 27:903-911

8. Geyer JT, Ferry JA, Longtine JA, Flotte TJ, Harris NL, Zukerberg LR (2010) Characteristics of cutaneous marginal zone lymphoma with marked plasmacytic differentiation and a T-cell rich background. Am J Clin Pathol 133(1):59-69

9. Magro CM, Porcu P, Ahmad N, Klinger D, Crowson AN, Nuovo G (2004) Cutaneous immunocytoma: a clinical, histologic, and phenotypic study of 11 cases. Appl Immunohistochem Mol Morphol $12: 216-224$

10. Sander CA, Kaudewitz P, Kutzner H, Simon M, Schirren CG, Sioutos N, Cossman J, Plewig G, Kind P, Jaffe ES (1996) T-cellrich B-cell lymphoma presenting in skin: a clinicopathologic analysis of six cases. J Cutan Pathol 23:101-108 
11. Delville JP, Heimann P, Housni HE, Boutriaux M, Jeronnez A, Remmelink M, Lasudry J, Pradier O, Kentos A (2007) Biclonal low grade B- celllymphoma confirmed by both flow cytometry and karyotypic analysis, in spite of a normal kappa/lambda Ig light chain ratio. Am J Hematol 82:473-480

12. Sanchez ML, Almeida J, Gonzalez D et al (2003) Incidence and clinicobiologic characteristics of leukemic B-cell chronic lymphoproliferative disorders with more than one B-cell clone. Blood 102:2994-3002

13. O'Reilly RA (1998) Splenomegaly in 2,505 patients at a large university medical center from 1913 to 1995.1963 to 1995 : 449 patients. West J Med 169:88-97

14. Gao X, Li J, Lin J, Liu D, Yu L, Wang Q (2017) High-grade transformation in a splenic marginal zone lymphoma with a cerebral manifestation. Am J Case Rep 18:611-616
15. Camacho FI, Mollejo M, Mateo MS, Algara P, Navas C, Hernández JM, Santoja C, Solé F, Sánchez-Beato M, Piris MA (2001) Progression to large B-cell lymphoma in splenic marginal zone lymphoma: a description of a series of 12 cases. Am J Surg Pathol 25:1268-1276

16. Dungarwalla M, Appiah-Cubi S, Kulkarni S, Saso R, Wotherspoon A, Osuji N, Swansbury J, Cunningham DC, Catovsky D, Dearden CE, Matutes E (2008) High-grade transformation in splenic marginal zone lymphoma with circulating villous lymphocytes: the site of transformation influences response to therapy and prognosis. $\mathrm{Br} \mathrm{J}$ Haematol 143:71-74

17. Piris MA, Onaindia A, Mollejo M (2017) Splenic marginal zone lymphoma. Best Pract Res Clin Haematol 30(1-2):56-64

Publisher's note Springer Nature remains neutral with regard to jurisdictional claims in published maps and institutional affiliations. 